\title{
New Waste Material to Enhance the Performance of Grounding System
}

\author{
Nazatul Shiema Moh Nazar*, Suresh Thanakodi, Hazuwan Muhammad \\ Department of Electrical and Electronic Engineering, Faculty of Engineering, \\ National Defence University of Malaysia, 57000 Kuala Lumpur, Malaysia \\ ${ }^{*}$ Corresponding author, e-mail: nazatul.shima@upnm.edu.my
}

\begin{abstract}
This paper presents the new waste material to enhance the grounding system application by using Rice Straw Ashes as backfill to reduce the grounding resistance of the grounding system. Due to the importance of the grounding system, this paper discussed the effectiveness of the grounding system after using the additive material. The additive material that used are rice straw ash and bagasse ash. The technique that used in this paper is a vertical type because more economical to install. From the result, it was found that depth of electrode and soil treatment has an impact in reducing the grounding resistance. In addition, Rice Straw ashes provide a better grounding performance comparable to Bagasse ashes.
\end{abstract}

Keywords: rice straw, bagasse ash, soil treatment

Copyright $\odot 2017$ Universitas Ahmad Dahlan. All rights reserved.

\section{Introduction}

All electrical system is equipped with grounding system. A good grounding system is required for protection of buildings and installations against lightning. Grounding system also provides a path to earth of enough current-carrying capacity so that protection of conductors and equipment against fault to earth is provided. The grounding resistance need to be effectively improved by getting a small grounding resistance to obtain a good grounding system [1]. Besides that, safety of human and animal life by limiting touch and step voltages to safe values. In addition, correct operation of the electricity supply network and to ensure good power quality. The effective grounding system must provide a low impedance path to ground for personnel and equipment protection and effective circuit relaying. Besides that, provide correction allowance or correction resistance to various soil chemical to ensure continuous performance during the life of the equipment being protected.

A grounding system refers to metallic wire of various geometric shapes and sizes, acting as electrodes and buried in the soil. There are many types of electrode rod used as a grounding system, but only two types are commonly used, vertical rod and horizontal rod. The most elementary and most economical configuration of ground electrode is a vertical rod electrode. This type of electrode is extremely effective for small installations. For horizontal rod type, it is mainly used for large electrical installations and is usually buried in a shallow or moderate depth [2].

Majority of grounding system uses salt $(\mathrm{NaCl})$ as backfill with soil to reduce the resistivity. But when rains, these salts will dissolve and loss the effectiveness. It was found that $\mathrm{NaCl}$ addition successfully decrease the value of soil resistance, but the effect is temporary and at the end of the monitoring period the value of resistivity has increased back to almost the original resistivity value [3]. In order to maintain the low resistance, additional salt will be needed and it will make the higher cost. So that, the alternative way is needed to overcome this problem. From this problem, it consolidates the reason for Rice Straw ashes and Bagasse ashes are selected to be as backfilled soil for the grounding system.

There are three objectives of this paper. First and foremost, to study the grounding performance of local soil that use new waste addictive material. Second, to reduce the grounding resistance of the grounding system. Lastly, to study the effectiveness of the grounding system after using the addictive material. There are several scopes for this paper. Firstly, the material used as grounding rod is red copper rod. Second, depth of electrode pushed 
into ground depend on the length of the rod. The depth is 0.6 meter and 1.1 meter. Third, a technique that use is vertical type. Fourth, rice straw ash and bagasse ash use as backfill material to obtain a low resistance reading.

\section{Parameters to Improve the Grounding System 2.1. Purpose of Grounding System}

There are five main important things for the circuit and system to be grounded [4]. First, when lightning happened. Second, when line surges. Third, when accidental contact with higher electric potential lines. Fourth, to stabilize the electric potential to ground during normal operations. Fifth, to expedite the overcurrent device operation in case of ground fault on a solidly grounded system. The stranded conductor of a grounded system produces a lowresistance path for error-current through the overcurrent protective device to determine the length of time a fault exits. It is important to plan to help the overcurrent protection device to operate as soon as possible and keep the electricity as clean as possible [4]. There are three reasons to keep the impedance in low value [5]. First, to minimize the voltage to ground. Second, to smooth the operation of the circuit overcurrent protective devices. Third, drain leakage, static, and unwanted noise-making currents to ground.

The proper installation of effective grounding works to establish protection for the individual from voltage and current. With grounding, the voltage is eliminated. Then there is nothing to drive the current through the body and the lower apposition path allows the current to flow through something other than the physical structure [5]. In a script entitled "Grounding and Bonding" that brought out by $\mathrm{T}$. Condition as wiring regulations, it explained the meaning of grounding which is the system that connects the general pile of land with the exposedconductive-parts of an installation via the conductors, the main grounding terminal (MET) and the circuit conductor [6].

It also stated the purpose of source grounding. The purpose is to safeguard the security of the supply network by preventing the potential of the lives conductors (with respect to the earth) rising to a value consequential loss of supply. Other than that, purpose of electrical equipment grounding also available in this book. It submitted that the connection of all exposed conductive-parts of the facility to the intend means of grounding, and is always used when protection against direct contact is by automatic disconnection of supply and earth equipotential bonding. Besides that, the aim of such grounding is to facilitate the automatic functioning of the protective devices for protection against electric shock and earth fault protection, hence that the supply to the faulty circuit is disconnected immediately [6].

\subsection{General Practical Ground Electrodes}

The word "ground" is determined as a directing connection by which a circuit or gear is identified with the earth. The connection is utilized to assemble and keep up as nearly as would be prudent the capability of the ground on the circuit or equipment connected with it. A "ground" comprises of a grounding conductor, a holding connector, its grounding electrode, and the soil in contact with the terminal.

A grounding system refers to metallic wire of various geometric shapes and sizes, acting as electrodes and buried in the soil. The vertical rod, horizontal electrode, ring electrode and the grounding grid are four commonly used grounding electrodes as illustrated in Figure 1. The most elementary and most economical configuration of ground electrode is a vertical rod electrode. This type of electrode is extremely effective for small installations. It is more effective when the seat layer of soil penetrated has lower impedance. Actually, if using a single stick, generally do not reduce the resistance, so it is necessary to add a number of rods connected in parallel [3].

The horizontal ground is mainly used for large electrical installations and is usually buried in a shallow or moderate depth. The ring electrode is an instance of the horizontal grounding grid and is now and again utilized as fringe ground conductors around structures like wind turbines. In order to find even lower ground resistance, the horizontal ground grid can be augmented with vertical poles, which are normally inserted at the fringe of the grounding grid [3]. 


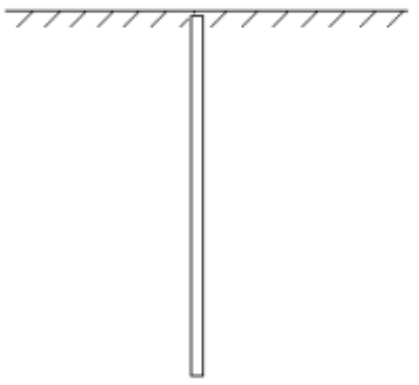

Vertical electrode

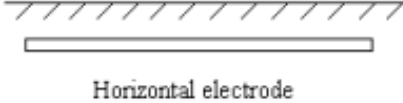

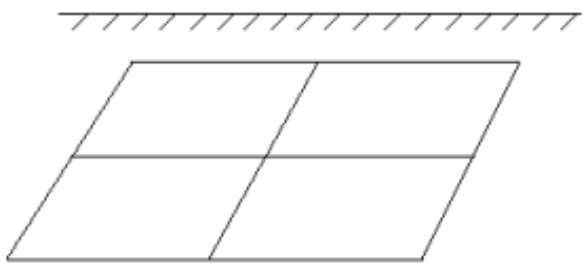

Earthing grid

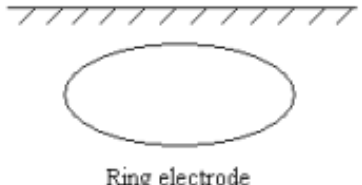

Ring electrode

Figure 1. Types of Grounding Resistance System of Transmission Tower [3]

\subsubsection{Vertical Ground Electrodes}

The vertical ground electrodes are the most usual type of electrodes in grounding systems and usually the most economical to install. The long vertical electrodes can be used to reach a low ground resistance in high resistivity soil and are driven to a few meter depth when soil conditions allow. A series of high impulse current tests were held on four vertical ground electrodes in different soils (shale, mud, crushed rock, sand) by Bellaschi. The current range was from $2 \mathrm{kA}$ to $8 \mathrm{kA}$ and rise times varied from $6 \mu \mathrm{s}$ to $13 \mu \mathrm{s}$. Again, the impulse resistance was obtained as the ratio of peak voltage to peak current and, in agreement with previous work, a fall of impulse resistance with increase of current was observed [7].

The impulse resistance dropped below the low frequency resistance, and this characteristic was attributed to the soils electrical breakdown. It was confirmed that the size, shape and the system of the ground electrode were factors contributing to the grounding characteristics. The impulse resistance was determined for both plus and negative polarities; the divergence was found to be really low. Deeply buried type or shaft type grounding can be used when more profound underground soil resistivity is lower. The resistance can be lower by getting an advantage of nearby natural grounding or the groundwater level is high and wet [7]. Figure 2 shows the vertical ground electrode grounding system.

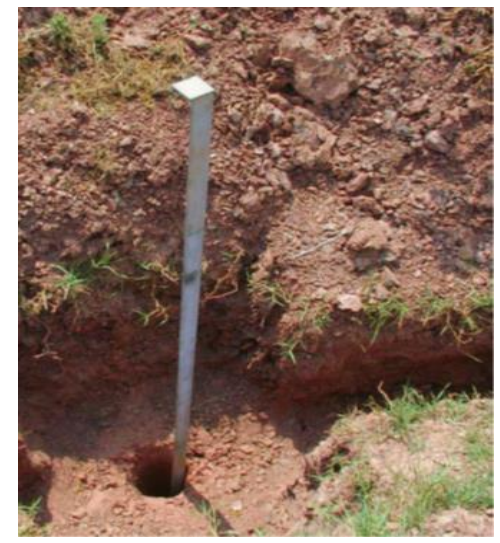

Figure 2. Vertical Ground Electrode Grounding System 


\subsubsection{Horizontal Ground Electrodes}

Horizontal ground electrodes can be used to reduce the ground resistance of a substation or a tower base footing. The horizontal ground electrode applied to tower lines may be continuous or non-continuous and lay between towers and parallel to the line conductors. Alternatively, conductors may be placed perpendicular to the transmission line and enhanced arrangements using 4 points, 6 points or 8 points star can be used [2]. Geri and Garbagnati conducted field trials on a horizontal steel ground electrode to investigate its impulse response. Impulse currents with magnitudes from 5 to $26 \mathrm{kA}$ and a rise time of $2.5 \mu \mathrm{s}$ were injected into the $5 \mathrm{~m}$ long electrode. The impulse resistance was observed to decrease as the current peak increased, and this reduction was attributed to the non-linear ionization phenomenon on the soil.

This technique can be connected when there is moderately great even horizontal position and soil conditions close to the tower. Even horizontal mode has minimal effort on the grounds that simple to introduce it. It cannot cut down the power frequency grounding resistance, but also effectively diminishes adequate resistance while the expansion is not far [2]. Figure 3 shows the horizontal ground electrode grounding system.

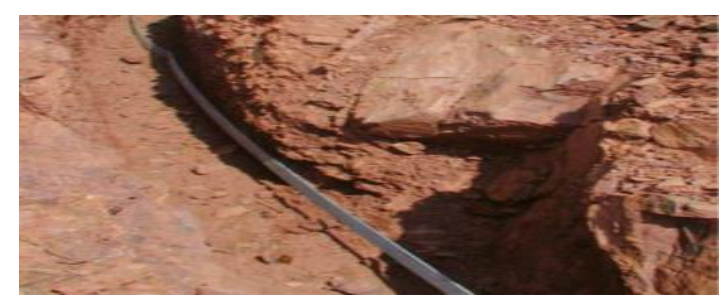

Figure 3. Horizontal Ground Electrode Grounding System

\subsection{Soil Resistivity}

Soil resistivity plays a significant role when defining the intent of the grounding system for new installations of transmission cable to meet ground resistance requirements. Preferably a location with the lowest possible resistance is the best position to make a transmission tower. The soil resistivity relies on moisture content, temperature, and soil composition. The resistivity of the soil will change geographically and at different soil depths because the soil is seldom consistent. Moisture content changes occasionally, differs as indicated by the way of the sub layers of earth $[8,9]$.

It is advised that the ground rods be placed as deep as possible into the earth because soil and water are more stable at deeper stratum, at the water table if possible. Ground rods also should be founded where there is a stable temperature, as example below the freeze outline. For a grounding system to be efficient, it should be designed to resist the toughest possible clime [1]. The soil resistivity is differing by its location. The soil at flat area usually has a lower soil resistivity compare to the hill area. This is because the characteristic of hill area that have stony soil and rock. Table 1 shows the soil resistivity on different type of soil.

\begin{tabular}{cc} 
Table 1. Soil Resistivity on Different Type of Soil \\
\hline Soil & Resistivity(ohm-cm) \\
\hline Surface soil and loam & $100-5000$ \\
Clay & $200-10000$ \\
Sand and gravel & $5000-100000$ \\
Surface limestone & $10000-1000000$ \\
Shales & $500-10000$ \\
Sandstone & $2000-200000$ \\
Granites and basalts & 100000 \\
Decomposed gneisses & $5000-50000$ \\
Slates & $1000-10000$ \\
\hline
\end{tabular}




\subsection{Backfill for Grounding}

Backfill material is often used where grounding conditions are poor. The backfill was prepared by mixing salt and local soil or by saturating the soil backfill with a salt-water solution. Backfill other than soil was also used because soil is not always easily recovered from some drilled or blasted holes and because unfrozen material is difficult to find during the winter. Absorbent paper saturated with a salt solution and compacted in the hole around the electrode was evaluated as a soil substitute in several installations.

\subsection{Rice Straw Ash as Backfill Material}

Rice straw is the waste products of the operation to obtain rice apart from rice grains. Ashes of rice straw can be obtained from the combustion process. There are two types of rice straw ash, which can be obtained from the stubble burning activities that is white ashes (carbonfree) and black ashes. The black ashes are in black color. They still have unburned carbon compare to the white carbon that completely burn its carbon. The black carbon is denser, while the white carbon is lighter. Ashes in general, have low resistivity significantly.

Rice straws have about $15 \%$ ash after burning, thus for $1000 \mathrm{~kg}$ of rice straw being burned, $150 \mathrm{~kg}$ ash is produced and contain about $82 \%$ of silica. Because of the high silica in the rice straw ashes it made the rice straw is one of the hydrophilic polymer that are easy to absorb water [10]. While the resistance of the hydrophilic polymer will make the ashes to reduce the amount of water being absorbed. So to take the ashes to absorb more water, the high quantity of ashes needs to be applied. Figure 4 shows the burning process of rice straw ashes and Figure 5 shows the sample of rice straw ashes.

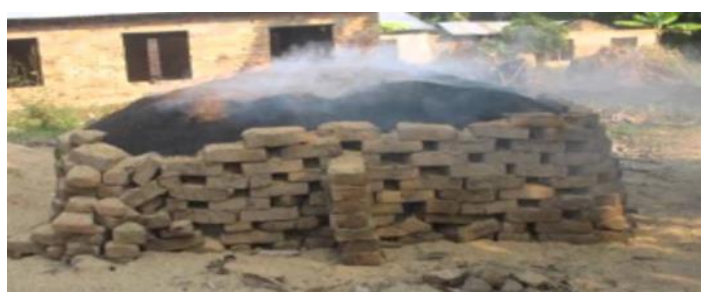

Figure 4. Burning Process of Rice Straw Ashes

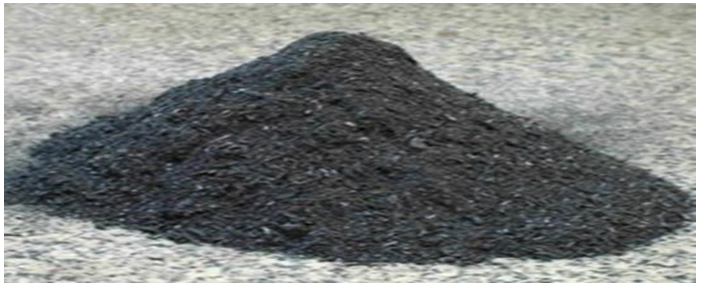

Figure 5. Sample of Rice Straw Ashes

\subsection{Bagasse Ash as Backfill Material}

The sugarcane bagasse consists of approximately $50 \%$ of cellulose, $25 \%$ of hemicellulose and $25 \%$ of lignin. Each ton of sugarcane generates approximately $26 \%$ of bagasse (at a moisture content of $50 \%$ ) and $0.62 \%$ of residual ash. The residue after combustion presents a chemical composition dominates by silicon dioxide (SiO2). Bagasse ash mainly contains aluminum ion and silica [11]. Figure 6 shows the bagasse ash sample.

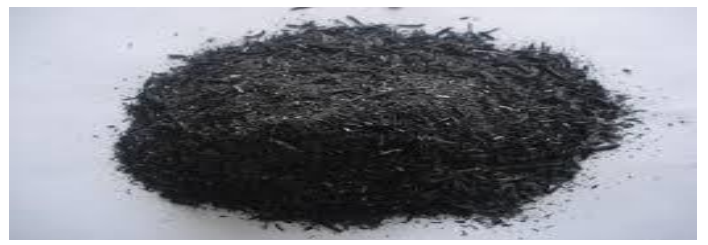

Figure 6. Sample of Bagasse Ash

\section{Methodology}

\subsection{Selection Technique to Improve Grounding System}

TNB's transmission tower specification currently states that the tower footing resistance of the $132 \mathrm{kV}$ and $275 \mathrm{kV}$ transmission towers has to be lower than $10 \Omega$, while for $500 \mathrm{kV}$ transmission towers the tower footing resistance has to be below $5 \Omega$ [9]. Those values were 
chosen because it is effective and low cost. After the selected techniques were applied, the reading of the grounding resistance was taken and compared.

\subsubsection{Increase the depth of the electrode rod}

One very efficient way of lowering the ground resistance has increased the depth of the ground electrode. In this technique, electrode rod is pushed deeper into the soil. The deeper the electrode pushes into the soil, the lower the grounding resistance. The spacing of additional rods needs to be at least equal to the depth of the driven rod so that the additional electrodes will be effective [7].

\subsubsection{A Soil treatment}

Some other style to lower the earth resistivity is to handle the soil with a salt, such as copper sulfate, magnesium sulfate, or sodium chloride. Combined with moisture, the salts leach into the soil to reduce earth resistivity. In this paper, the local soil combined with salt, $2 \mathrm{~kg}$ of rice straw ash and $2 \mathrm{~kg}$ of bagasse ash. Figure 7 shows the methods for the soil treatment.

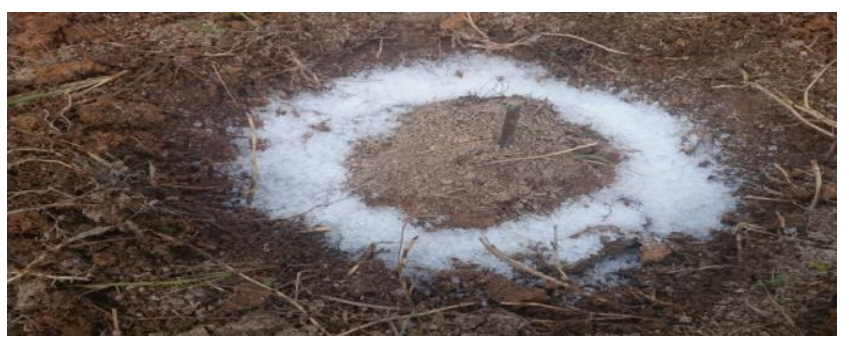

Figure 7. Salt is put around the electrode rod

\subsection{Conducting Testing}

In order to achieve the objectives of this paper, the electrode rod will be planted into the ground near the transmission tower. The electrode rod pushed to a depth of 0.2 meter, 0.4 meter, 0.6 meter, 0.8 meter, 1.0 meter and 1.2 meter into the ground. This experiment runs for several days. Grounding resistance for each electrode rod was taken. Then the data were analyzed and compared to validate the effect of the technique that chosen.

\subsection{Testing Procedures}

i. The selector switches in OFF position; the instrument was connected as shown in Figure 8. Potential stakes and current stakes are driven into the earth, forming a straight line with the test electrode.

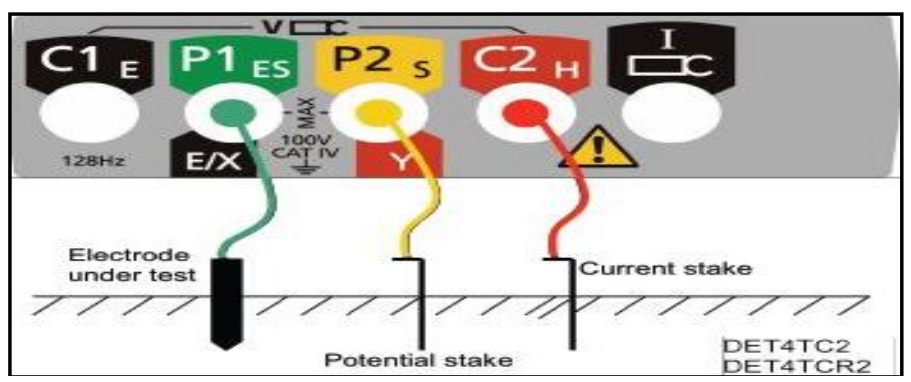

Figure 8. Connection of electrode under test and stake

ii. The length of potential stake to electrode under test is at least $60 \%$ of the length of the current stake to electrode under test. In this testing, length of potential stake is 3.6 meter and length of current stake is 6 meter. 
iii. The selector switch is set to the 3 points resistance measurement marked " $3 p$ ".

iv. The desired voltage was selected using 50 volts.

v. The TEST button was pressed and released. By pressing and holding the TEST button, the resistance measurement will be continually updated and displayed.

vi. In a short period, a resistance will be displayed in ohm and recorded in the table. The readings were taken three times and were averaged.

vii. These readings are taken to get all the data.

\section{Results}

\subsection{Result: Depth of Electrode Rod}

As shown in Figure 9, it clearly shows that 1.2 meter depth has the lowest grounding resistance. This result shows that the grounding resistance is proportional to the depth of the electrode rod seen the deeper electrode rod planted into ground, the lower the value of grounding resistance obtain. The lower resistance is needed so that lightning strikes or fault current can discharge to the ground as fast as possible.

From the data taken, the grounding resistance can reduce up to $59 \%$ for a difference of 1.0 meter depth. The deeper electrode can reduce grounding resistance because the longer electrode rod has a larger area to discharge fault or lightning strike to the ground. When the electrode rod has larger area, it can quickly discharge the fault or lightning strike in a short time. Therefore, the depth of the electrode rod can be one of the techniques to reduce the grounding resistance of the transmission line tower. The deeper the electrode rod put in the ground, the lower its grounding resistance.

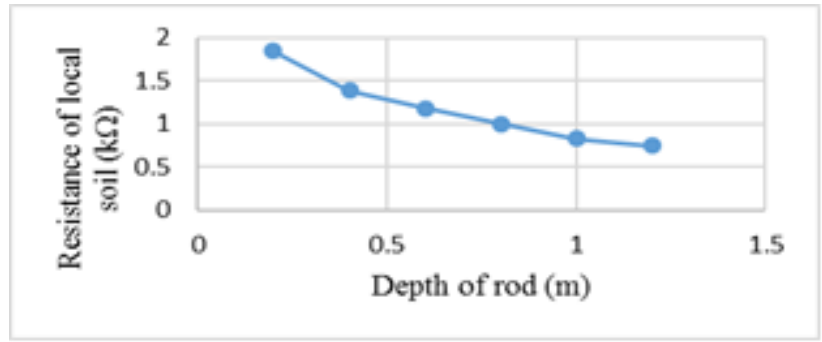

Figure 9. Resistance of Local Soil $(\mathrm{k} \Omega)$ versus Depth of Rod $(\mathrm{m})$

\subsection{Result: Effect of Soil Treatment}

Figure 10 to Figure 15 shows the resistance of soil treatment versus depth of rod. However, the lowest grounding resistance is $0.074 \mathrm{k} \Omega$ or $0.000074 \Omega$ as shown in Figure 13. It shows that the electrode rod with (bamboo salt + rice straw ash) addition that represented by Figure 13 has lower grounding resistance compare to the others. Due to salts are added around the electrode rod, it will leach and react with the ground. The salt will migrate its charged ion to the electrode rod from the copper electrode rod has the ability to attract charged particles and reduce the soil resistivity. When the soil resistivity is low, there is easy to discharge the fault compare to ground that have high soil resistivity.

This testing was made not to put salt into the all the transmission tower, but to show the difference in soil resistivity can affect the grounding resistance. Usually, the higher place like hill has a higher soil resistivity. This is because the higher place has stony soil, loamy soil and rock. It means if the transmission tower is set up there, it will have a poor grounding system. Preferably a location with the lowest possible resistance is the best position to make a transmission tower. Hence the need to move the transmission tower to the suitable location for grounding spot increase in the overall cost of installation because it will far away from the facility. Therefore, soil treatment can use as a solution to this problem. Although the testing to reduce the grounding resistance not according to the requirements of TNB which is below $10 \Omega$, but it can be concluded that the chosen technique can improve the grounding resistance of the transmission tower by reducing the grounding resistance. 


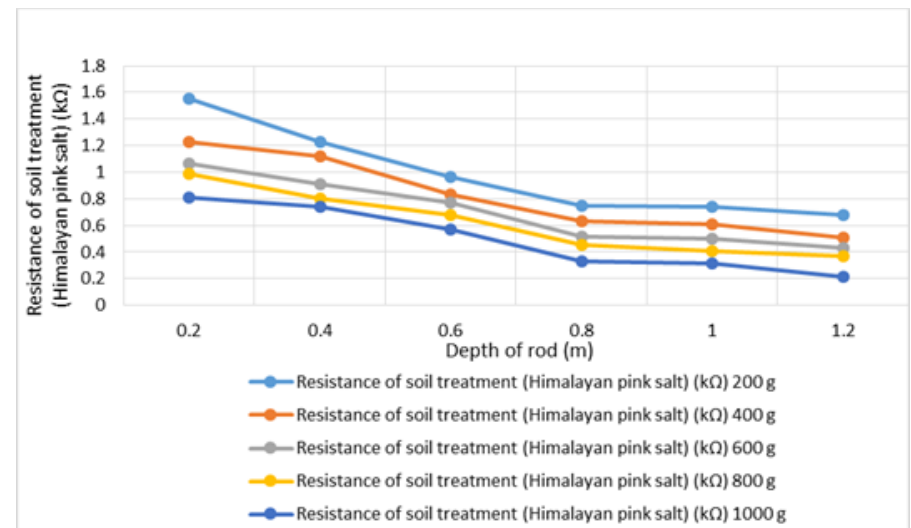

Figure 10. Resistance of Soil Treatment (Himalayan Pink Salt) $(k \Omega)$ versus Depth of Rod $(m)$

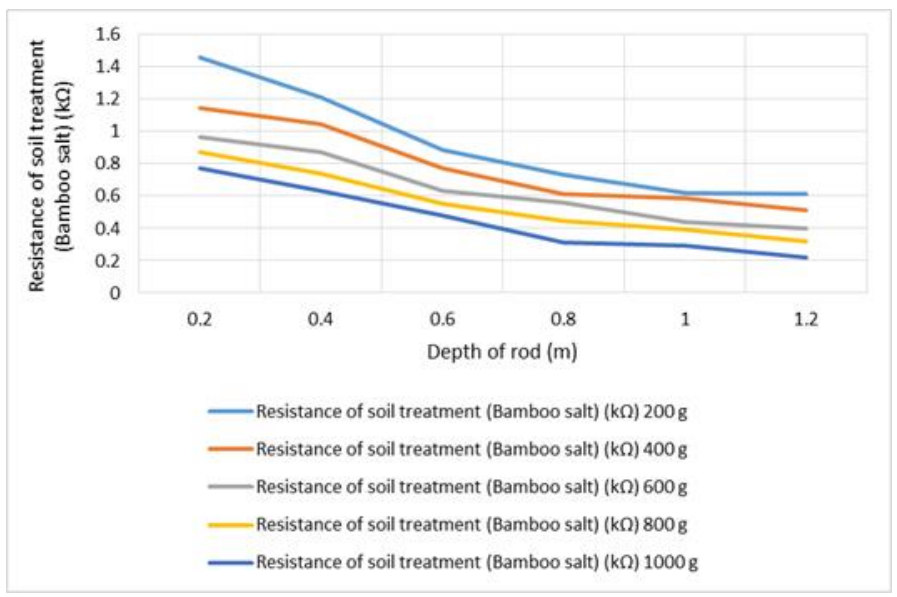

Figure 11. Resistance of Soil Treatment (Bamboo Salt) $(\mathrm{k} \Omega)$ versus Depth of Rod $(\mathrm{m})$

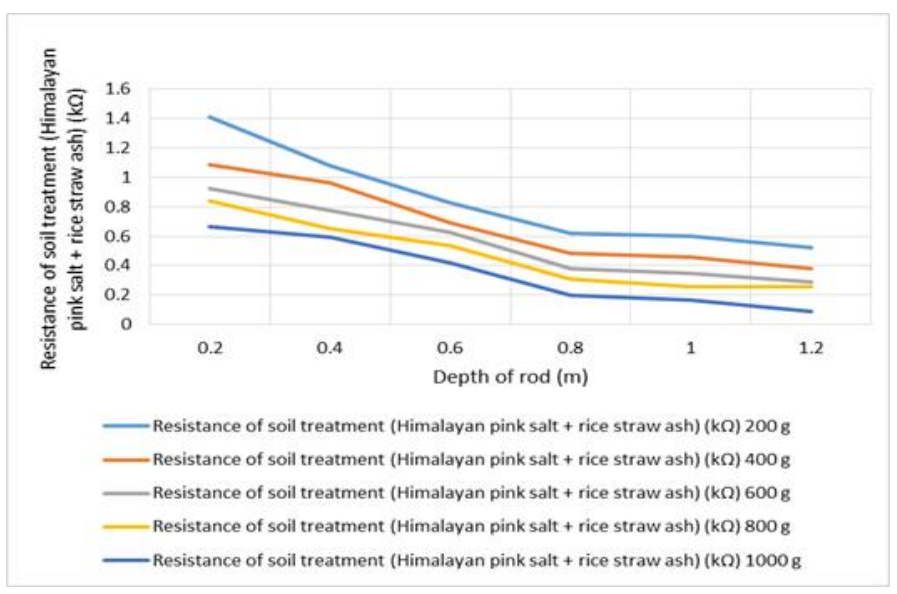

Figure 12. Resistance of Soil Treatment (Himalayan Pink Salt + Rice Straw Ash) $(k \Omega)$ versus Depth of Rod $(\mathrm{m})$ 


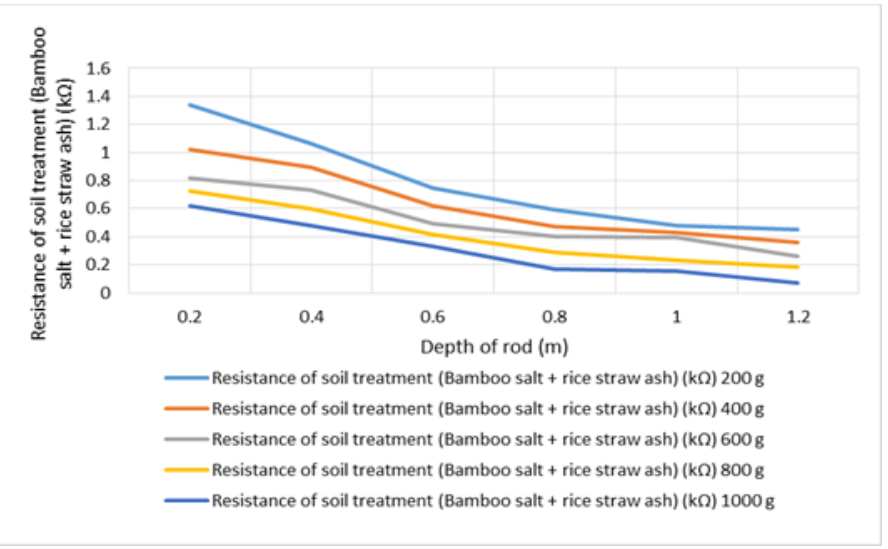

Figure 13. Resistance of Soil Treatment (Bamboo Salt + Rice Straw Ash) $(k \Omega)$ versus Depth of Rod (m)

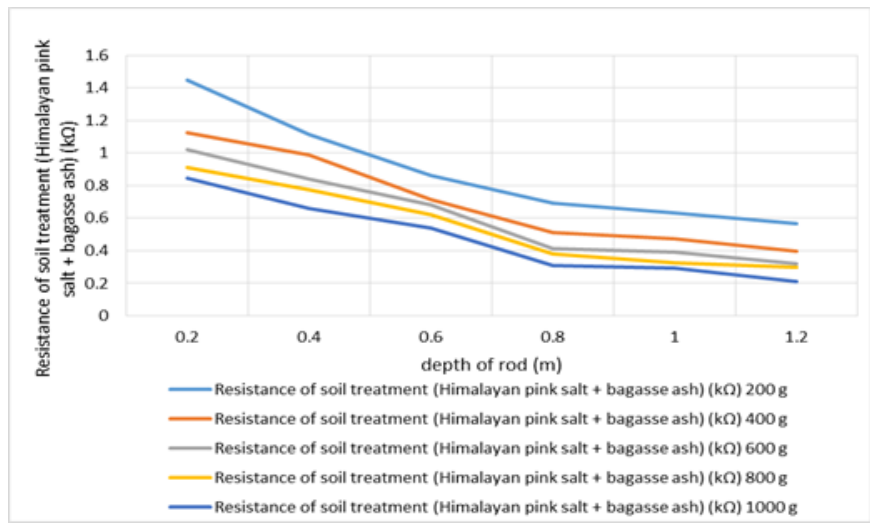

Figure 14. Resistance of Soil Treatment (Himalayan Pink Salt + Bagasse Ash) $(k \Omega)$ versus Depth of Rod (m)

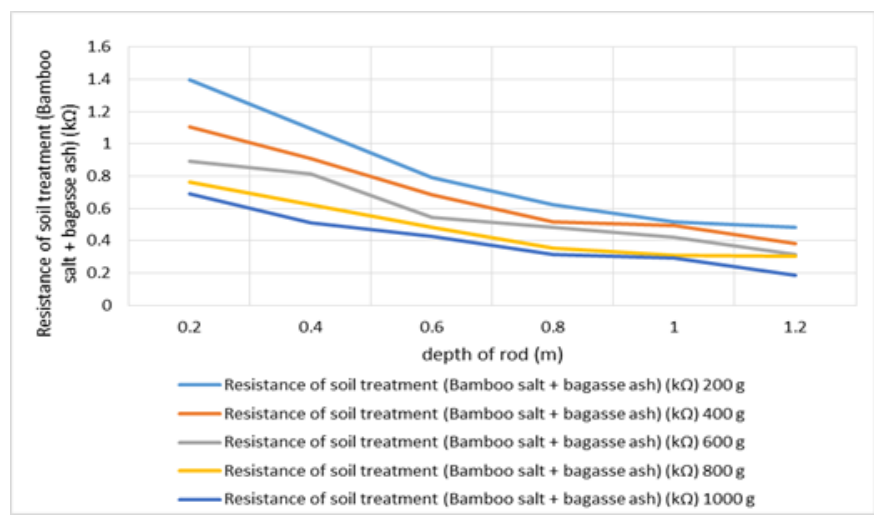

Figure 15. Resistance of Soil Treatment (Bamboo Salt + Bagasse Ash) $(k \Omega)$ versus Depth of Rod (m)

\section{Conclusion}

There are two techniques can be used to reduce the grounding resistance which is increasing the depth of the electrode rod and the soil treatment by using rice straw ashes and bagasse ashes as backfill material. Both techniques are capable to reduce the grounding 
resistance. However, this testing cannot reach the TNB's transmission tower specification. TNB regulates that for the $132 \mathrm{kV}$ and $275 \mathrm{kV}$ transmission towers, the grounding resistance has to be

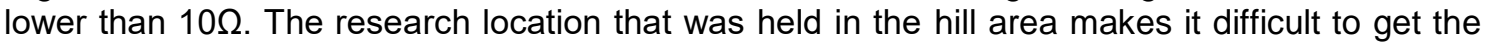
rounding resistance below $10 \Omega$. As a conclusion, it is important to have a better grounding system. In order to make sure the grounding system is in good condition, it is compulsory to retain a low grounding resistance. Therefore, it can prevent lightning interface of transmission line and to assure security operation of the power system.

\section{References}

[1] Lee WC, Mohd ZAAK, Chandima G, Wan FWA. Analysis of Earth Resistance of Electrodes and Soil Resistivity at Different Environments. 2012.

[2] Y Khan, NH Malik, AA Al-Arainy, MI Qureshi, FR Pazheri. Efficient Use of Low Resistivity Material for Grounding Resistance Reduction in High Soil Resistivity Areas. 2010.

[3] A Abreu, AlL Design. Experience in Material Selection for Grounding Systems for Power Transmission Towers. 2014; 4: 1-5.

[4] Don J, K Nithiyananthan. Effective Methods for Power Systems Grounding. 2008.

[5] RB Carpenter, JA Lanzoni. Designing for A Low Resistance Earth Interface (Grounding). 2007.

[6] T Conditions. Characterisation of earthing systems under high frequency and transient conditions. 1999: 188-192.

[7] R Zeng, J He, Z Wang, Y Gao. Analysis on Influence of Long Vertical Grounding Electrodes on Grounding System for Substation. 2000: 1475-1480.

[8] C Boaventura, J Osvaldo, S Paulino. The influence of seasonal soil moisture on the behavior of soil resistivity and power distribution grounding systems. Electr. Power Syst. Res. 2014.

[9] N Azlina, A Rahman, A Marzuki, A Marican, AM Davies, M Zainal, A Ab, N. Abdullah. A Practical Method for Optimised Earth Electrode Designs at Transmission Towers Exposed to Lightning. 2011: 131-134.

[10] A Nurnadia, MD Intan, WARW Aizan, S Hanizam. Development of HDPE/Rice Straw Composite for Construction Application via Injection Mold Teenique.

[11] R Srinivasan, K Sathiya. Experimental Study on Bagasse Ash in Concrete. 2010. 